\title{
OPTIMASI BATUBARA TIPIS (THIN COAL SEAM) DI PIT A SITE SENAKIN PT ARUTMIN INDONESIA
}

\author{
Yogie Reza Pratama ${ }^{1)}$, Abdul Kahar ${ }^{1)}$ dan Arif Ridwan ${ }^{1)}$ \\ ${ }^{1)}$ Departemen Engineering, PT. Arutmin Indonesia
}

\begin{abstract}
ABSTRAK
Konservasi cadangan batubara adalah upaya dalam rangka optimalisasi pengelolaan, pemanfaatan, dan pendataan batubara secara terukur, efisien, bertanggung jawab, dan berkelanjutan. Pengelolaan ini dilaksanakan dengan cara melakukan proses penambangan sesuai dengan perencanaan untuk memperoleh recovery penambangan yang optimal serta mengendalikan dilusi dan kehilangan (losses) batubara. Di dalam KEPMEN ESDM No. 1827 K/30/MM/2018 lampiran VII disebutkan bahwa cut off thickness minimum batubara adalah $30 \mathrm{~cm}$. Batas minimum ini diterapkan dalam rangka mengoptimalkan recovery penambangan dan meminimalisir adanya dilusi yang diperoleh selama proses penambangan. Risiko dari penggalian batubara dengan ketebalan kecil dari $30 \mathrm{~cm}$ adalah semakin besarnya potensi terjadinya dilusi. Hal ini dikarenakan semakin banyak luasan permukaan batubara yang bersentuhan langsung dengan material pengotor di bagian roof dan floor dibandingkan dengan penggalian batubara. Kondisi tersebut diperparah dengan adanya losses saat menggunakan alat gali yang berukuran besar. Dilusi dan losses ini akan berdampak kepada menurunnya kuantitas, kualitas dan recovery pengolahan batubara. Dalam paper ini akan dibahas mengenai upaya konservasi batubara dari PT. Arutmin Indonesia Site Senakin di Pit A dengan melakukan kajian tentang optimasi penambangan lapisan batubara tipis (thin coal seam) dengan tebal minimum $20 \mathrm{~cm}$. Batas ketebalan minimum ini merupakan batas optimal dari kemampuan peralatan yang digunakan di Senakin. Karakteristik Pit A yang memiliki beberapa sisipan di dalam batubara juga menjadi faktor kunci apakah batubara tipis tersebut layak untuk ditambang. Semakin tebal material sisipan maka kadar abu akan semakin tinggi dan ini akan menjadi acuan terkait keekonomisan batubara tersebut. Secara operasional penentuan ketebalan batubara ini dilakukan oleh Geologist secara aktual di lapangan. Selanjutnya dilakukan analisa sampel batubara tersebut dan jika secara kualitas layak untuk ditambang maka akan dilanjutkan ke dalam tahap operasional penambangan dengan menggunakan alat kelas 20 ton dan 30 ton serta dengan pengawasan khusus selama proses pembersihan, pengumpulan, pemuatan sampai dengan pengangkutan. Batubara tipis tersebut kemudian diolah oleh Washplant yang ada di Senakin dengan recovery pengolahan sekitar 79,3\%. Dengan optimasi ini maka akan didapatkan tambahan batubara dengan range $20-30 \mathrm{~cm}$ sekitar 1,49\% dari jumlah cadangan sebelumnya. Berdasarkan hasil dari metode penambangan dan pengolahan tersebut, batubara tipis di Pit A dapat dioptimalkan dalam rangka memenuhi konservasi batubara serta meningkatkan revenue perusahaan dan pemerintah.
\end{abstract}

Kata Kunci : Batubara tipis, Recovery penambangan, Recovery pengolahan, Konservasi batubara, Kadar Abu

\section{ABSTRACT}

Coal reserve conservation is an effort to optimize the management, utilization and data collection of coal in a measured, efficient, responsible and sustainable manner. This Management is applied by carrying out the mining process in accordance with the plan to obtain optimal mining recovery with controlled coal dilution and losses. 
According to Ministerial Decree No. 1827 K / 30 / MM / 2018 in appendix VII stated that the minimum coal cut-off thickness is $30 \mathrm{~cm}$. Coal thickness minimum limit is applied in order to optimize mining recovery and minimize dilution during the mining process. The risk of coal extraction with thickness less than $30 \mathrm{~cm}$ has extra potency for dilution because more of coal surface area directly contact with impurity materials on the roof and floor rather than coal excavation. That condition is exacerbated by the lost when using a large digging tool. Dilution and loss will have an impact to the decline of the quantity, quality and recovery of coal processing. This paper will discussed about coal conservation efforts from PT. Arutmin Indonesia Site Senakin at Pit A. PT. Arutmin Indonesia conducting a study on optimizing thin coal seam mining with a minimum thickness of $20 \mathrm{~cm}$. Regarding to the coal thickness minimum limit is the optimal limit of the equipment capabilities used at Senakin. The characteristic of Pit A which has several parting material in coal is also a key factor whether the thin coal is feasible to be mined or not. Parting material thickness will be impacted to the ash content and related to the coal economical. Coal thickness is measured by geologist in the field. Furthermore, the coal sample is analyzed and if it is qualified to be mined it will be proceed to the mining operation stage using 20 tons and 30 tons grade tools also with special supervision during the cleaning, collecting loading and hauling processes. Thin coal is processed using Washplant in Senakin with processing recovery around $79.3 \%$. This optimization method will be resulted an additional coal with a range about 20$30 \mathrm{~cm}$ around $1.49 \%$ of the amount of reserves. The result is thin coal in Pit A can be optimized in order to achieve coal conservation and increase company and government revenue.

Keywords: Thin coal, mining recovery, recovery processing, coal conservation, ash content

\section{A. LATAR BELAKANG}

Indonesia merupakan salah satu negara yang kaya akan sumber daya alam, baik berupa minyak dan gas bumi, mineral dan batubara. Pasal 33 Undang-Undang Dasar 1945 mengamanatkan bumi, air dan kekayaan alam yang terkandung di dalamnya dikuasai oleh negara dan dipergunakan sebesar-besarnya untuk kemakmuran rakyat. Amanat UUD 1945 ini merupakan landasan pembangunan pertambangan dan energi untuk memanfaatkan potensi kekayaan sumber daya alam dan energi yang dimiliki secara optimal.

Indonesia merupakan salah satu negara penghasil batubara terbesar di asia tenggara dengan produksi sebesar \pm 400 juta ton setiap tahun. Kondisi jumlah cadangan batubara di Indonesia pada tahun 2018 sebesar 24.240 Juta Ton (Badan Geologi, 31 Desember 2017). Dengan mempehitungkan peningkatan produksi dan penambahan cadangan batubara tiap tahunnya maka diperkirakan cadangan batubara akan habis pada tahun 2067 atau 48 Tahun lagi dari sekarang. Diperlukan penerapan konservasi cadangan batubara agar sisa cadangan batubara yang ada saat ini dapat dimanfaatkan dengan baik sesuai dengan amanat undang-undang yang berlaku.

Konservasi cadangan batubara adalah upaya dalam rangka optimalisasi pengelolaan, pemanfaatan, dan pendataan batubara secara terukur, efisien, bertanggung jawab, dan berkelanjutan. Pengelolaan ini dilaksanakan dengan cara melakukan proses penambangan sesuai dengan perencanaan untuk memperoleh recovery penambangan yang optimal serta mengendalikan dilusi dan kehilangan (losses) batubara. Dilusi adalah masuknya material pengotor ke dalam batubara pada kegiatan pertambangan dan losses adalah kehilangan batubara akibat dari proses penambangan.

Di dalam KEPMEN ESDM No. 1827 K/30/MM/2018 lampiran VII disebutkan bahwa cut off thickness minimum batubara adalah $30 \mathrm{~cm}$. Batas minimum ini diterapkan dalam rangka mengoptimalkan recovery penambangan dan meminimalisir adanya dilusi yang diperoleh selama proses penambangan. 
Risiko dari penggalian batubara dengan ketebalan kurang dari $30 \mathrm{~cm}$ adalah semakin besarnya potensi terjadinya dilusi. Hal ini dikarenakan semakin banyak luasan permukaan batubara yang bersentuhan langsung dengan material pengotor di bagian roof dan floor dibandingkan dengan penggalian batubara. Kondisi tersebut diperparah dengan adanya losses saat menggunakan alat gali yang berukuran besar. Dilusi dan losses ini akan berdampak kepada menurunnya kuantitas, kualitas dan recovery pengolahan batubara.

Saat ini Site Senakin sudah melakukan pengendalian dilusi dan losses ini dengan baik. Hal ini diwujudkan dengan pencapaian persentase recovery penambangan sebesar 98\% pada tahun 2018 . Pencapaian ini dilakukan dengan penerapan alat gali dengan kelas yang sesuai, pengawasan khusus saat proses pengambilan batubara, penggunaan alat angkut yang dilengkapi dengan tail gate, pengaturan jarak lubang ledak dengan batubara, serta mewajibkan kesesuaian desain lereng dengan kondisi aktual di lapangan agar batubara tidak ada yang dilusi dan losses.

Metode penambangan yang diterapkan yaitu dengan metoda tambang terbuka open pit dengan system konvensional yaitu dengan menggunakan alat gali-muat (excavator) dan truck pengangkut, untuk menggali dan memindahkan bantuan penutup serta mengambil batubara dan mengangkutnya ke fasilitas pengolahan batubara. Karakteristik batubara bituminous disini memiliki kadar abu cukup tinggi. Abu (ash) merupakan kandungan residu dari bahan atau material yang tidak dapat dibakar/dioksidasi oleh oksigen.yang umumnya terdiri dari senyawa-senyawa silika dioksida ( $\mathrm{SiO} 2)$, kalsium oksida $(\mathrm{CaO})$, karbonat dan mineral-mineral lainnya. Dikarenakan batubara disini memiliki kadar abu mencapai 18-25\%, maka dilakukan proses pencucian di Washplant dengan perolehan berdasarkan data historikal sebesar $83 \%$.

Dalam rangka meningkatkan upaya konservasi batubara, dilakukanlah kajian tentang optimasi penambangan lapisan batubara tipis (thin coal seam) dengan range $20-30 \mathrm{~cm}$ di Pit A. Dengan optimasi lapisan batubara tipis (thin coal) ini diharapkan dapat meningkatan cadangan batubara di PT. Arutmin Indonesia Site Senakin Pit A.

\section{B. METODOLOGI PENELITIAN}

Masalah-masalah yang dibahas dalam skripsi ini diselesaikan dengan menggunakan pendekatan penelitian deskriptif. Batubara tipis di makalah ini didefinisikan sebagai batubara yang memiliki rentang ketebalan $20-30 \mathrm{~cm}$. Adapun data yang akan ditampilkan pada skripsi ini dilakukan dengan teknik pengumpulan data sebagai berikut :

1) Studi literatur

Studi literatur dilakukan pada sebelum, saat dan sesudah penelitian dilakukan. Literatur yang digunakan berasal dari buku, jurnal penelitian dan laporan-laporan yang berhubungan dengan penelitian ini.

2) Pengumpulan Data

- Data Primer

Data yang langsung diperoleh dari pengamatan di lapangan, seperti data alat gali batubara, ketebalan dan litologi batubara secara aktual khususnya batubara tipis, pengambilan data koordinat dan luasan area batubara tipis, efektivitas pekerjaan alat gali batubara untuk pengambilan batubara tipis.

- Data Sekunder

Data yang diperoleh dari arsip, meliputi spesifikasi alat gali batubara, ketebalan dan litologi batubara dari model geologi, jumlah cadangan batubara yang tersisa di Pit A tahun 2019, dan data historikal pencucian batubara. 
3) Analisa Data

Data-data yang telah diperoleh kemudian diolah dan dianalisis dari literatur-literatur berhubungan dengan masalah tersebut, ialah sebagai berikut:

- Mengamati litologi serta ketebalan batubara secara model dari data lubang bor dengan kondisi batubara di lapangan secara actual.

- Menganalisa alat gali batubara yang digunakan serta kemampuan penggalian minimum batubara yang bisa diambil.

- Menganalisa efektivitas alat gali untuk batubara tipis untuk meminimalisir potensi kontaminasi.

- Menghitung cadangan batubara Pit A Tahun 2019 (sebelum optimasi batubara tipis).

\section{HASIL DAN PEMBAHASAN}

\section{C.1. Kondisi Litologi Batubara}

Endapan batubara Senakin masuk kedalam Formasi Tanjung, batubara disini memiliki kemiringan relatif ke arah timur dengan kemiringan $5^{\circ}-14^{\circ}$. 1 group seam terdapat 3 seam utama sebagai target penambangan yaitu SU, SM dan SL. Terdapat pula seam Pengapitan menjadi Pengapitan atas dan bawah yang biasa dinamakan seam PU dan PL. Stratigrafi lapisan pembawa batubara pada daerah Senakin dapat dilihat pada Gambar 1.

Data stratigrafi batubara yang berasal dari hasil data bor (lihat Gambar 1.) menunjukkan ketebalan masing-masing lapisan batubara Senakin sebagai berikut :

- Lapisan PU memiliki ketebalan rata-rata 0,44 m, $\min 0,15 \mathrm{~m}, \max 1,4 \mathrm{~m}$. Lapisan PL memiliki ketebalan rata-rata $0,56 \mathrm{~m}, \min 0,15 \mathrm{~m}, \max 1,98 \mathrm{~m}$.

- Lapisan SU1 memiliki ketebalan rata-rata $0,3 \mathrm{~m}, \min 0,01 \mathrm{~m}, \max 0,8 \mathrm{~m}$.

- Lapisan SU2 memiliki ketebalan rata-rata $0,3, \min 0,02 \mathrm{~m}, \max 1,15 \mathrm{~m}$.

- Lapisan SM1 memiliki ketebalan rata-rata 1,42 m, $\min 0,09 \mathrm{~m}, \max 3,05 \mathrm{~m}$.

- Lapisan SM2 memiliki ketebalan rata-rata 1,14 m, $\min 0,01 \mathrm{~m}, \max 2,72 \mathrm{~m}$.

- Lapisan SL pada Pit A memiliki 2 lapisan yang terpisah menjadi SL1 dan SL2. Lapisan SL memiliki ketebalan rata-rata $0,78 \mathrm{~m}$, $\min 0,03 \mathrm{~m}$, dan $\max 2,28 \mathrm{~m}$. Lapisan SL1SL2 merupakan gabungan 2 lapisan dikarenakan parting diantaranya memiliki ketebalan $<15 \mathrm{~cm}$.

Berdasarkan hasil analisa dari data bor, batubara senakin memiliki kadar abu dengan rentang 18-25\%. Angka Hardgroove Grindability Index (HGI) batubara <40 yang menunjukkan bahwa batubara disini cukup keras untuk dilakukan penggalian.

\section{C.2. Data Alat Gali Batubara}

Pekerjaan penggalian tanah diawali dengan bucket dari alat gali dijulurkan ke depan batubara. Kemudian apabila bucket telah pada posisi yang diinginkan bucket diayunkan atau dicangkulkan kebawah dengan lengan bucket diputar kearah atas. Setelah bucket terisi penuh dengan batubara maka bucket diangkat dan dilakukan swing ke tempat penumpukan batubara. Site Senakin menggunakan 2 alat gali utama untuk melakukan aktivitas cleaning, stocking dan loading yaitu PC200 dan H350.

Terdapat 2 jenis bucket yang digunakan oleh alat gali batubara. PC200 menggunakan flat bucket untuk aktivitas cleaning dan mengumpulkan sisa batubara yang ada di floor. $\mathrm{H} 350$ menggunakan teeth bucket untuk aktivitas stocking dan loading tumpukan batubara. Flat bucket dapat digunakan untuk stocking jika karakteristik batubaranya tidak terlalu keras. Keunggulan flat bucket adalah ujung bucket yang pipih sehingga potensi kontaminasi saat stocking menggunakan flat bucket dapat diminimalisir. 
Sedangkan kelebihan teeth bucket memiliki ujung yang tajam sehingga memudahkan untuk memberai batubara yang keras tetapi disisi lain memiliki potensi kontaminasi saat melakukan stocking.

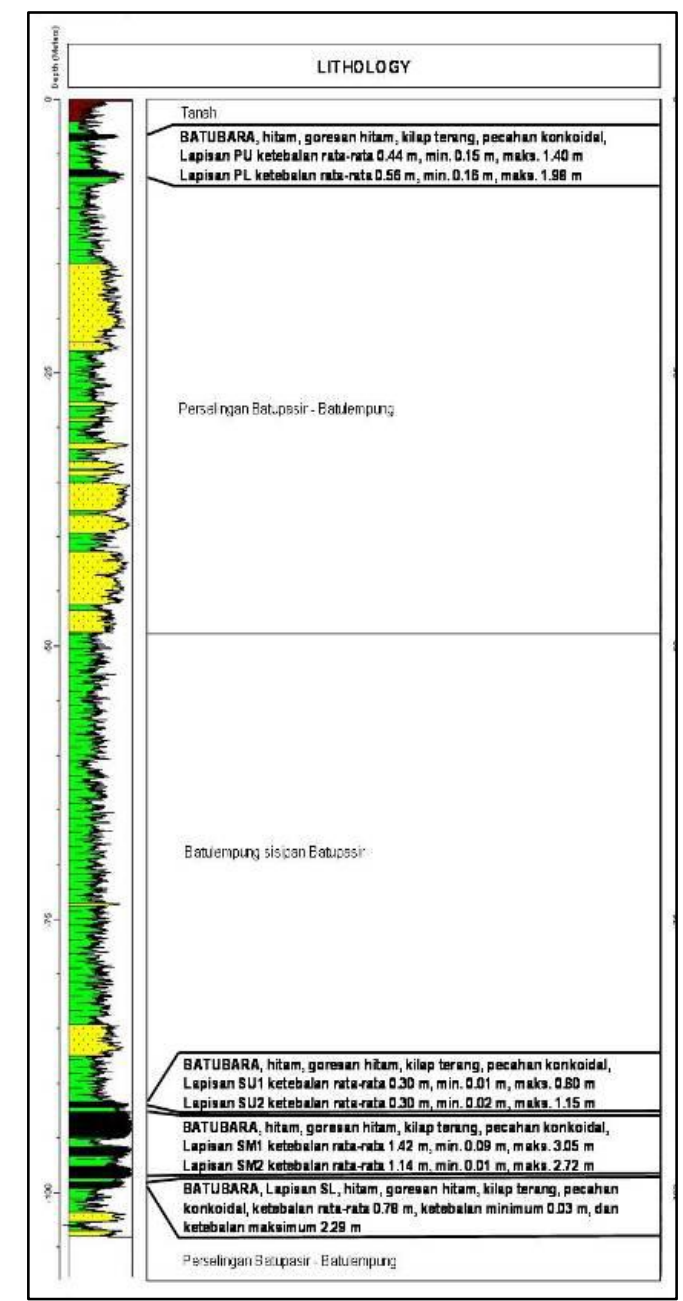

Sumber : Feasibility Study PT. Arutmin Indonesia, 2009

Gambar 1. Litologi Batubara Site Senakin (Data Bor)

Dari hasil pengamatan di lapangan, ketebalan batubara minimum yang dapat diambil dengan menggunakan PC200 (flat bucket) dan H350 (teeth bucket) adalah batubara yang memiliki ketebalan minimum $20 \mathrm{~cm}$. Dengan ditetapkannya ketebalan minimum ini, maka secara operasional penambangan harus mengikuti kaidah penambangan dengan baik dan waspada selama prosesnya sehingga dapat meminimalisir potensi adanya dilusi batubara.

\section{C.3. Data Jumlah Cadangan Batubara Pit A Tahun 2019 (Sebelum Optimasi Batubara Tipis)}

Penambangan di Pit A terdiri dari 16 blok yaitu blok 10-26 dengan jarak setiap blok adalah $125 \mathrm{~m}$. Hasil perhitungan cadangan Pit A pada setiap bloknya pada tahun 2019. 
Tabel 1. Total Jumlah Cadangan Batubara di Pit A Tahun 2019 Sebelum Optimasi

\begin{tabular}{cr}
\hline Block & Coal Volume (ton) \\
\hline B10 & 78 \\
B11 & 3.501 \\
B12 & 3.522 \\
B13 & 168 \\
B14 & 16.414 \\
B15 & 32.312 \\
B16 & 67.334 \\
B17 & 255.365 \\
B18 & 265.503 \\
B19 & 221.797 \\
B20 & 216.952 \\
B21 & 199.355 \\
B22 & 175.957 \\
B23 & 174.867 \\
B24 & 197.074 \\
B25 & 210.708 \\
B26 & - \\
TOTAL & 2.041 .647 \\
\hline
\end{tabular}

Sumber : PT. Arutmin Indonesia, 2019

\section{C.4. Upaya Optimasi Batubara Tipis Pit A}

\section{C.4.1. Observasi Litologi Batubara}

Observasi ini dilakukan oleh tim geologist dari PT. Arutmin Indonesia dengan kontraktornya saat terdapat area ekspos batubara baru. Tujuan dilakukannya observasi ini adalah untuk mengidentifikasi litologi batubara secara aktual dilapangan. Dengan mengetahui litologi batubara tersebut akan ditentukan apakah batubara tersebut layak untuk ditambang berdasarkan karakteristik fisiknya serta ketebalannya. Pengecekan ini dapat dilakukan dengan membuat saluran/lubang terbuka (open channel) menggunakan excavator. Ketebalan batubara ini diukur secara manual dengan membedakan perlapisan dari dinding batubara yang terbuka ((lihat Gambar 2.). Ketebalan batubara minimum yang akan dilakukan optimasi dengan yaitu batubara yang memiliki rentang ketebalan $20-30 \mathrm{~cm}$.

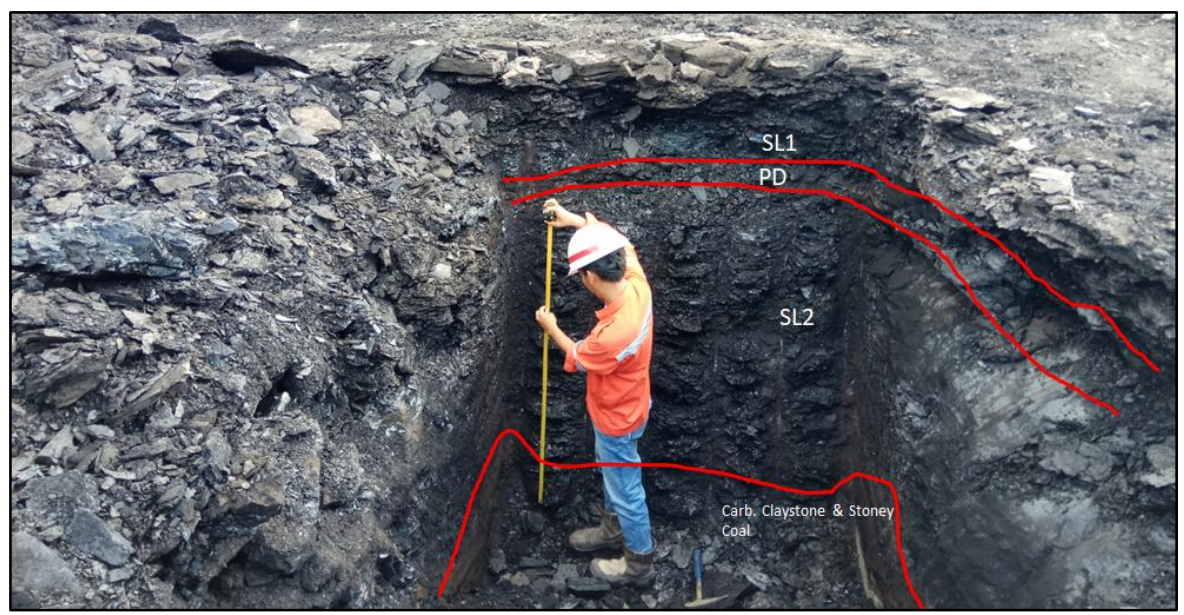

Sumber : PT. Arutmin Indonesia, 2019

Gambar 2. Pengamatan dan Pengukuran Ketebalan Batubara Secara Aktual 


\section{C.4.2. Channel Sampling Batubara}

Setelah dilakukan pengamatan oleh tim geologist dan dinyatakan bahwa batubara tersebut layak untuk ditambang berdasarkan karakteristik fisik dan ketebalannya maka kemudian dilakukanlah channel sampling pada dinding lapisan batubara. Channel sampling dilakukan dengan mengambil tiap bagian lapisan dengan jarak (interval) dan kedalaman tertentu dari roof hingga lapisan jarak dan kedalamannya disesuaikan dengan jumlah sampel, dengan memperhatikan kondisi lapisan batubara dan ukuran partikel yang dibutuhkan. Tujuan dilakukannya channel sampling ini adalah untuk mengetahui kualitas batubara.

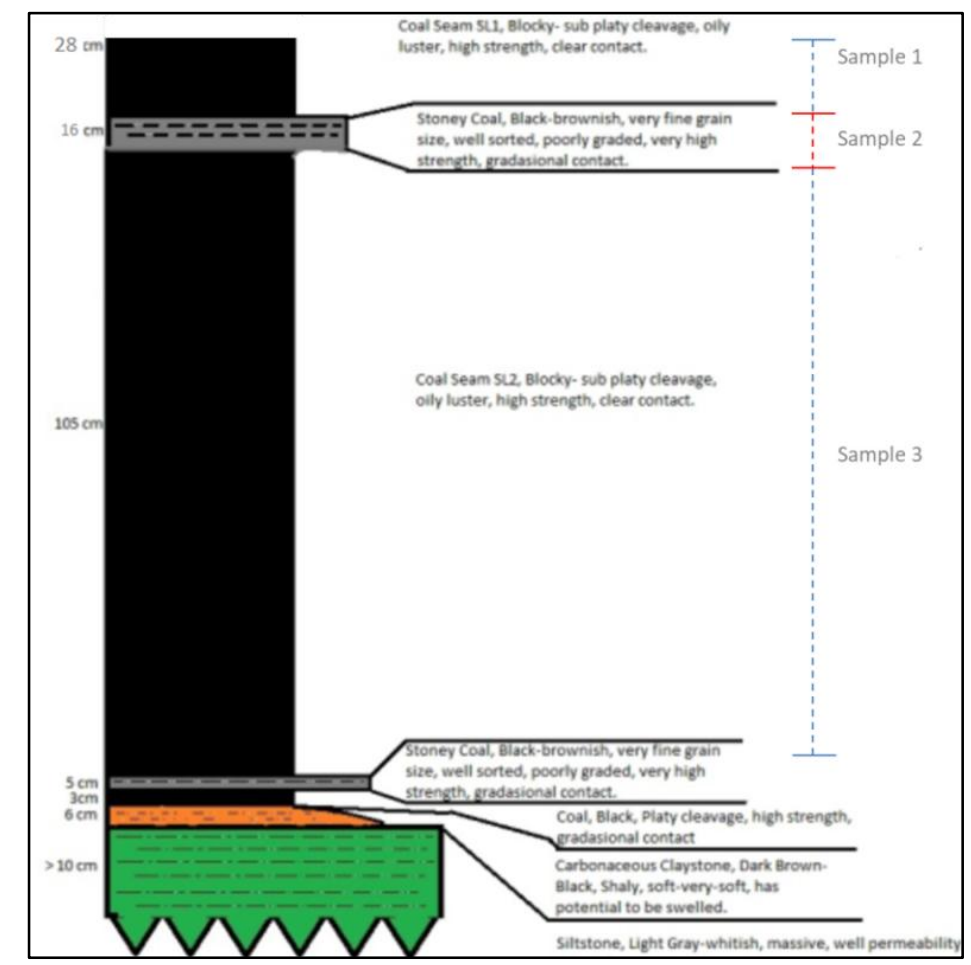

Sumber : PT. Arutmin Indonesia, 2019

Gambar 3. Channel Sampling Lapisan Batubara

Sampel yang diambil sebanyak 3 buah berdasarkan gambar 3. Sampel batubara ini kemudian dikirim ke laboraturium untuk dianalisa kadar abu (ash), total sulfur (TS), total moisture (TM), inherent moisture (IM), calorivic value (CV), relative density $(\mathrm{RD})$ dan volatile matter (VM). Dengan mengetahui kualitas batubara maka dapat ditentukan apakah batubara tersebut layak secara kualitas untuk ditambang serta memudahkan penempatan batubara di Run of Mine (ROM) Washplant sebelum dicuci.

\section{C.4.3.Pengambilan Data Koordinat dan Boundary Batubara Tipis}

Setelah channel sampling dilakukan, kemudian tim survey akan mengambil data koordinat dan boundary area batubara tipis. Data koordinat dan boundary ini kemudian di plot di peta (lihat Gambar 4.) kemudian digunakan untuk membandingkan kualitas dan ketebalan batubara dengan model geologi. Data tersebut diperlukan untuk perhitungan luas dan volume penambangan batubara tipis. 


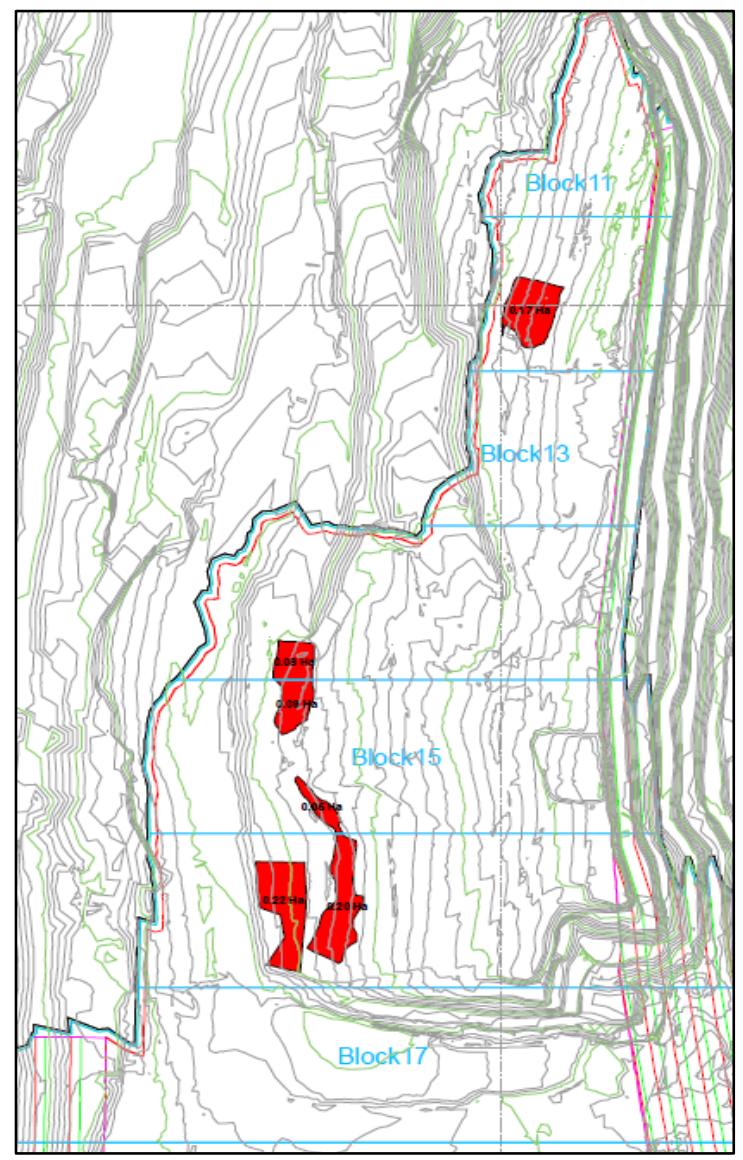

Sumber : PT. Arutmin Indonesia, 2019

Gambar 4. Pemetaan Lokasi Batubara Tipis di Pit A Senakin

\section{C.4.4. Kegiatan Operasional Penambangan Batubara Tipis}

Setelah batubara tipis ini dinyatakan layak berdasarkan kualitasnya maka akan dilanjutkan ke tahap operasional penambangan. Metode penambangan batubara tipis sebagai berikut :

a) Cleaning \& Stocking Batubara Tipis

Tahap awal yang dilakukan adalah melakukan cleaning dibagian roof batubara menggunakan PC200 Flat Bucket. Setelah area bersih dari material roof maka akan dilakukan percobaan stocking menggunakan PC200, jika batubara tersebut dapat terberai maka stocking akan dilanjutkan. Pada saat kondisi batubara keras maka stocking akan digantikan dengan H350 Teeth bucket. Batubara ini akan di tumpuk pada area yang bersih dan terpisah dari tumpukan batubara yang lain. Posisi bucket saat melakukan stocking harus berada diantara $75^{\circ}-90^{\circ}$ (lihat Gambar 5.) dengan dinding batubara agar potensi kontaminasi dapat diminimalisir. Stocking merupakan hal yang paling penting dalam mengoptimasi batubara tipis ini sehingga ditempatkan pengawas/Pit Geologist khusus yang memastikan tidak adanya kontaminasi batubara saat proses stocking berlangsung. 


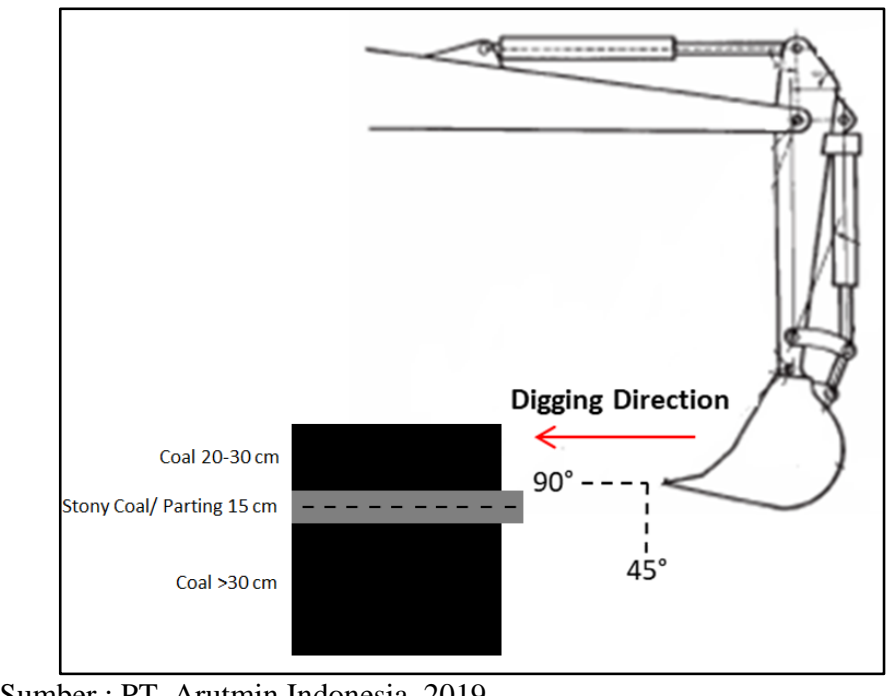

Sumber : PT. Arutmin Indonesia, 2019

Gambar 5. Sudut Gali Optimum Penambangan Batubara Tipis

b) Pengumpulan Sisa Floor Batubara \& Loading Tumpukan Batubara Tipis

Tahap selanjutnya adalah mengumpulkan sisa batubara tipis menggunakan PC200. Batubara yang telah dikumpulkan kemudian digabung dengan tumpukan batubara tipis yang sudah ada sebelumnya (lihat Gambar 6.). Loading batubara ini menggunakan H350 dan dimuat ke truck kelas 25 ton dengan tail gate.

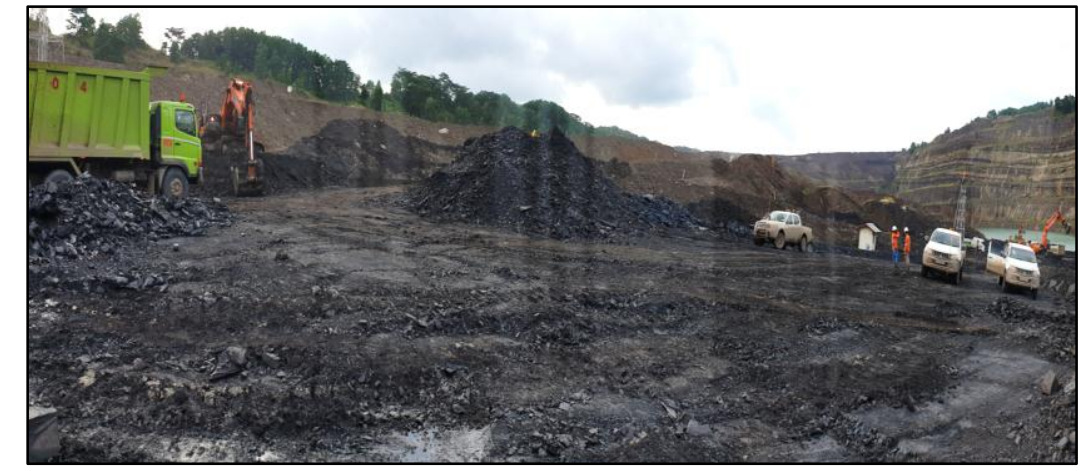

Sumber : PT. Arutmin Indonesia, 2019

Gambar 6. Kondisi Akhir Area Kerja Batubara Tipis

c) Pengangkutan Batubara Tipis ke Washplant

Batubara tipis tersebut kemudian diangkut menuju ROM Washplant. Penempatan tumpukan batubara tipis tersebut harus terpisah dengan batubara yang lain untuk memudahkan mengidentifikasi sumber batubara saat dilakukan proses pencucian.

d) Pencucian Batubara Tipis

Pencucian batubara di Site Senakin menggunakan Washplant yang pengolahannya didasarkan pada perbedaan spesific gravity (SG). Batubara memiliki $S G$ 1.3-1.4 dan material pengotor memiliki $S G>1.5$. Proses pengolahan dilakukan dengan Jigging yang akan membentuk stratifikasi dalam bed sehingga material pengotor cenderung tenggelam dan batubara bersih akan 
mengapung di atas. Pencucian batubara ini bertujuan untuk menurunkan kadar abu batubara menjadi $<12 \%$ sesuai dengan target pasar dari PT. Arutmin Indonesia.

Batubara tipis yang ditumpuk terpisah di ROM Washplant kemudian diolah secara khusus untuk mengetahui recovery perolehannya. Hasil pencucian batubara tipis sebagai berikut :

Tabel 2. Hasil Pencucian Batubara Tipis Pit A

\begin{tabular}{ccr}
\hline Feed Source & \multicolumn{2}{c}{ Thin Coal } \\
\cline { 2 - 3 } Trial & $(\mathbf{1})$ & $\mathbf{( 2 )}$ \\
\hline Feed (ton) & 1.402 & 1.458 \\
Feed Ash (\%) & 23,86 & 23,73 \\
Feed Sulphur (\%) & 0,40 & 0,42 \\
Product (ton) & 1.099 & 1.168 \\
Product Ash (\%) & 11,27 & 11,20 \\
Product Sulphur (\%) & 0,46 & 0,49 \\
Reject (ton) & 427 & 303 \\
Reject Ash (\%) & 59,25 & 50,21 \\
Yield (\%) & 78,39 & 80,14 \\
Average Yield (\%) & $\mathbf{7 9 , 2 8}$ & \\
Product Ash (\%) & $\mathbf{1 1 , 2 3}$ \\
\hline
\end{tabular}

Hasil diatas (lihat Tabel 2.) menunjukkan recovery perolehan dari pencucian batubara tipis sebesar 79,28\% dengan kadar abu produk $11,23 \%$. Recovery perolehan dari pencucian batubara tipis ini dibawah rata-rata recovery perolehan batubara normal yaitu sebesar $83 \%$ tetapi masih diatas target dari PT. Arutmin Indonesia dengan yield $>78,25 \%$. Sehingga, batubara tipis ini dapat diolah dan diproses dengan baik.

\section{C.4.5. Perhitungan Jumlah Cadangan Batubara Pit A (Setelah Optimasi Batubara Tipis)}

Hasil perhitungan cadangan batubara di Pit A termasuk batubara tipis yang dioptimasi dapat dilihat pada tabel 3.

Berdasarkan perhitungan diatas (lihat Tabel 3.), total volume tambahan batubara tipis yang dapat dioptimasi sebesar 30.347 ton. Peningkatan cadangan batubara dengan optimasi batubara tipis ini sebesar 1,49\% dari perhitungan total cadangan batubara. Perolehan produk batubara tipis setelah dicuci sebanyak 24.059 ton.

Tabel 3. Perhitungan Cadangan Batubara Pit A Tahun 2019 Setelah Optimasi

\begin{tabular}{crrr}
\hline Seam & $\begin{array}{c}\text { Coal Reserve Without } \\
\text { Thin Coal (ton) }\end{array}$ & $\begin{array}{c}\text { Coal Reserve Include } \\
\text { Thin Coal (ton) }\end{array}$ & $\begin{array}{c}\text { Variance } \\
\text { (ton) }\end{array}$ \\
\hline PU & 4.381 & 7.424 & 3.043 \\
PL & 22.187 & 26.155 & 3.968 \\
SU1 & 272.782 & 274.706 & 1.925 \\
SU2 & 390.600 & 390.820 & 220 \\
SM1 & 473.263 & 473.320 & 57 \\
SM2 & 317.514 & 336.986 & 19.473 \\
SL1 & 1.203 & 2.359 & 1.157 \\
SL1SL2 & 547.381 & 547.381 & - \\
SL2 & 12.337 & 12.843 & 506 \\
\hline Total & $\mathbf{2 . 0 4 1 . 6 4 8}$ & $\mathbf{2 . 0 7 1 . 9 9 5}$ & $\mathbf{3 0 . 3 4 7}$ \\
\hline
\end{tabular}




\section{KESIMPULAN}

Dari hasil dan pembahasan diatas maka dapat diambil kesimpulan sebagai berikut :

1) Upaya optimasi batubara tipis ini dilakukan dengan cara observasi litologi batubara, channel sampling \& pengambilan data survey, pengawasan khusus saat dilakukan proses operasional pengambilan batubara tipis dan penerapan sudut gali optimum $75^{\circ}-90^{\circ}$, dan pencucian batubara tipis.

2) Recovery perolehan batubara tipis setelah dicuci yaitu $79,3 \%$.

3) Peningkatan cadangan dengan memasukkan batubara tipis dalam perhitungan total cadangan batubara sebanyak 30.347 ton atau sebesar $1,49 \%$.

4) Perolehan produk batubara tipis sebanyak 24.059 ton.

\section{DAFTAR PUSAKA}

Azizah, N. A., Nurrachman, T., Medina, E., Hapsari, D. S. (2016) : Pencucian Batubara, Makalah Teknologi Batubara, 1-4, 5-37.

Arif, I (2014) : Batubara Indonesia, 1,19-20.

Bangun, A. F. (2009) : Alat-alat Gali, Pengembangan Tanah Mekanik (PTM) \& Alat-alat Berat, 16-18. Dirjen Minerba. (2019) : PRESENTASI RUANG LINGKUP ASPEK KONSERVASI DALAM KAIDAH TEKNIS PERTAMBANGAN YANG BAIK.

(2009) : KAJIAN KELAYAKAN PENGEMBANGANPENAMBANGAN BATUBARA DI PT ARUTMIN INDONESIA.

Spesifikasi alat gali PC200 Komatsu, data diperoleh melalui situs internet : https://www.ritchiespecs.com/model/komatsu-pc200-8-hydraulic-excavator. Diunduh pada tanggal 8 September 2019.

Spesifikasi alat gali H350 Hitachi, data diperoleh melalui situs internet : Diunduh pada tanggal https://www.hitachiconstruction.com/wp-content/uploads/2015/11/ZX350LC-5_specs.pdf. Diunduh pada tanggal 8 September 2019. 
PROSIDING TPT XXVIII PERHAPI 2019 